\title{
Do Principio Constitucional da Separação dos Poderes
}

\author{
Elio Solon de Pontes
}

No segundo semestre de 1954, o "Instituto Brasileito de Direito Público e Ciência Politica da Fundação Getúlio Vargas" proporcionou, a sessenta candidatos portadores de diploma de nível universitário superior ou com experiência de chefia administrativa superior a dois aṇ̦s, um Curso de Direito Público, ministrado pelos professôres Themístocles Cavalcanti, Hermes Lima, Victor Nunes Leal e Carlos Medeiros da Silva, logrando certificado de freqüência a quase totalidade dos inscritos e de aproveitamento apenas quatro.

Entre êstes o Sr. Elio Monnerat Solon de Pontes que defendeu tese subordinada ao tema "Do Princípio Constitucional da Separação dos Poderes", que haje publicamos.

Anteriormente, a "Revista do Serviço Público", em novembro 1953 'e julho de 1954 publicara, do mesmo autor, os trabalhos intitulados " $D a$ Biologia das Formas Administrativas" e "Da Publicação de Lei, Objeto de Veto Parcial, Antes da Apreciação dêste pelo Poder Legislativo", da último dos quais foi extraída separata, executada nas oficinas do Departamento de Imprensa Nacional.

Génese, evolução e aplicações do discutido princípio de MoNTESQuieU e sua explicação à luzz da doutrina organicista.

CAPÍTULO I

\section{I - PRECURSORES DE MONTESQUIEU - GÊNESE E EVOLUÇÃO DA SEPARAÇÃO DOS PODERES}

C

ONSEQÜÊNCIA direta de circunstâncias político-sociais predominantes, em dada época, os problemas de ciência política variam, profundamente, em função delas .

$\mathrm{Na}$ antiguidade clássica por exemplo, ante a solidez dos preconceitos aristocráticos de então, amoldavam-se os teóricos à ordem vigente, ao ponto de vermos Aristóteles, o único precursor de Montesquieu, fazer a apologia da escravidão.

Em que pese, realmente, o caráter nebuloso e obscuro da concepção do grande Aristóteles, êle concebia três poderes que, de certo modo, corresponderiam àquêles gerados de "O Espírito das Leis". Eram êles:

$1^{\circ}$ ) O Poder deliberante, exercido pela Assembléia Popular; 


\section{2. ${ }^{\circ}$ A Autoridade, que corresponderia ao Executivo; \\ 3..$^{\circ}$ O Juiz.}

Ressalve-se, entretanto, que tais poderes, expostos no Livro VI, Capítu$\operatorname{los} 11$ a 13 da "Política". possuíam atribuições de natureza heterogênea, eram desprovidos de autonomia e sem limites reconhecíveis, como o demonstra BLUNSTSCHLI em sua "Teoria Geral do Estado", 3. a edição Francesa, páginas 458 a 462 .

Muitos anos mais tarde, quando imperava o absolutismo dos reis, o eminente filósofo inglês, JOHN LOCKE, no seu "Ensaio sôbre o Govêrno Civil", concebia a seguinte tríade de poderes:

1. $\left.^{\circ}\right)$ Poder Legislativo;

2. $\left.{ }^{\circ}\right)$ Poder Executivo;

3. $\left.{ }^{\circ}\right)$ Poder Confederativo.

Percebe-se que o pensamento político de então vacilava, diante do magno problema, que consistia em estabelecer os fundamentos básicos das Constituições democráticas modernas.

Campeavam, então, violentos choques de idéias e interêsses, estando a aspiração de independência das massas, a tanto comprimida, em vias de eclodir, irresistivelmente, até o advento de novo estado de equilíbrio, subordinado, então, a novos princípios e com respeito, acentuadamente, maior, à superioridade numérica das classes proletárias.

Curioso, a êsse respeito, é transcrever de J. J. Rousseau - o mais popular dos pensadores franceses, de então, do "Contrat Social", um trecho em que êle deixa refletir essa impetuosa pressão, em favor da representaçãot popular:

"La volonté générale ne se represente point; elle est la même ou elle est autre; il n'y a pas de milieu. Des députés du peuple ne sont donc ni ne peuvent être ses representants, ils ne sont que des comissionaires; ils ne peuvent rien conclure definitivement".

E' interessante notar que essas palavras, do mais vigorosamente original pensador político de então (palavras que traduzem, antes de tudo a instabilidade reinante na época, ainda que jamais tenham tido aceitação prática) encontrem, nos dias de hoje, como que longínquas e quase inexpressivas repercussões, na prática do "referendum" e, sobretudo na outorga de iniciativa das leis ao próprio povo, através de subscrições de no mínimo 30.000 assinaturas como por exemplo está previsto no artigo 72 da Constituição da Itália.

Embora não nos queiramos deter no assunto, parece importante acentuar que tais dispositivos nada têm de singular e excepcional nas Constituições européias de hoje, sejam elas de grandes ou pequenos estados. A Constituição do Estado Livre da Baviera, por exemplo, depois de proclamar, em seu artigo 7 , inciso 2, que "o cidadão exerce seus direitos participando das eleições, das iniciativas populares ("Volksbegehren") e dos referendos. ("Volkssentscheidungen") prevê minuciosamente, nos artigos 71 e seguintes, os casos em que as leis podem ser de iniciativa popular e pelo povo aprovadas 
O certo é que, em que pese a preocupação de Rousseau e a sua popularidade, exaltada por ORBAN e que obrumbou em sua Pátria, a do próprio MoNTESQuiEu, o certo é que o prestígio dêste, no campo da Ciência Política, foi maior na Inglaterra e nos Estados Unidos, desde então, e se revelou mais sólido e duradouro, através dos tempos, pela concepção do princípio da separação dos poderes", Legislativo, Executivo e Judiciário, exposta no seu livro monumental "L'Esprit des Lois".

Acentua o Professor Themistocles Brandão Cavalcanti, em uma das suas conferências, em síntese feliz, que

"a impressão dominante que deixa a leitura dos trabalhos de LOCKE e MoNTESQuieu é de que êles representavam uma reação contra o poder absoluto e tinham por objetivo primário estabelecer, através da separação dos poderes antes um equilíbrio entre êstes, evitandơ que cada um fôsse absoluto, a não ser em sua esfera própria e competência específica".

Êsses três poderes seriam, como já dissemos. o Legislativo, o Executivo e o Judiciário, cơm denominações ligeiramente diferentes:

"Il y a dans chaque Etat trois sortes de pouvoir: la puissance legislative, la puissance executrice des choses qui dependent du droit des gens et la puissance executrice de celles qui dependent du droit civil.

Par la première, le magistrat fait des lois pour un temps ou pour toujours et corrige ou abrege celles qui sont faites.

"Par la seconde, il fait la paix ou la guerre, envoie ou reçoit des embassades, établit la sûretá, previent les invasions.

"Par la troisième, il pûnit les crimes ou juge les differends des particuliers. On appelera cette dernière la puissance de jûger; et l'autre, simplement la puissance executrice de l'Etat'. MONTESQUIEU, "L'Esprit des Lois", apud Themistocles CavalCantr, opcsição citada).

Tais célebres períodos sintetizam os fundamentos de uma doutrina que tem, na expressão "Le pouvoir arrête le pouvoir" o indíciơ mais claro do seu objetivo supremo: o equilíbrio entre os poderes.

Ressalve-se, entre tanto, mais uma vez, que não teve MonTEsquieu, por objetivo, na época, o mesmo que, com base na sua doutrina visaram os seus seguidores.

"Parece até que um dos autores do "Federalista" e o pai do estatuto norte-americano, MADISON, atribuiu, conscientetmente, a MONTESQUIEU, idéias que êste não tinha, a fim de cobrir-se com a autoridade de um grande nome (SAInt Girons, "Essai sur la Séparation des Pouvoirs", 1881, págs. 89 a 100 e Walter Jellinek "O Estado Moderno e seu Direito", vol. II, pág. 162, nota 2) (Apud Carlos Maximiliano, Comentários, II, pág. 397).

Todavia o denunciado desvirtuamento, que chamaremos fecundo, provocaria, muitos anos depois, natural estranheza dos estudiosos.

Conta-nos, a propósito, o professor Themistocles Cavalcanti, que CHARLES EINSENMANN, em trabalho publicado em honra de CARRÉ DE MAL- 
BERG, chega a contestar que MONTESQUIEU se tenha referido, quer à separação funcional, quer à separação material das autoridades do Estado, antes, para êle, essas funções se confundem na mesma autoridade e no mesmo poder.

A nosso ver, separação relativa, orgânica, dos poderes é um pressuposto da teoria de Montesquieu em que pese essa cada vez mais necessária difusão de funções quase específicas de uns entre as atribuições de outros poderes, que tentaremos explicar. no capítulo II do presente estudo.

Apesar da discussão generalizada quanto ao têrmo separação dos poderes e seu conceito, o certo é que, na prática, sob o influxo das circunstâncias predominantes, três órgãos existem a constituir o Estado, subordinados a êste princípio que, ainda que elástico. flexível, discutido e aparentemente discutível, cada dia mais se consolida, cada vez mais firma o seu prestígio de dogma cada vez mais irresistivelmente é reconhecido como base do direito constitucional moderno, pedra de toque da técnica de govêrno em nossos dias e, sobretudo, como a lembrar os objetivos primordiais da idéia ao tempo em que foi gerada por Montesquieu, uma garantia para a sociedade contra eventuais aberrações liberticidas dos poderes constitucionais.

Há que discordar-se do eminente professor LAMBERT quando êle, depois de observar que a "Constituição dos Estados Unidos desenvolveu o dogma constitucional de MONTESQUIEU até suas últimas conseqüências lógicas" concluiu que "o princípio da separação dos poderes é incapaz de cumprir, por mais tempo, as suas promessas fundamentando a sentença no pressuposto de "um equilíbrio igualitário que êle pretende estabelecer entre os poderes constituídos" e prognosticando que o mesmo cederia mais cêdo ou mais tarde, sob a pressão da necessidade de uma unidade de ação no desenvolvimento da política nacional.

"Na Inglaterra e na França", exemplifica. "a rutura do equilíbrio se verificou em benefício do poder legislativo, que dominou, sob suas normas, os poderes coordenados e conseguiu instaurar, assim, o govêrno parlamentar. Nos Estados Unidos o desequilíbrio operou-se em benefício do poder judiciário, que passou a dominar os dois outros poderes, estabelecendo um govêrno dos juízes".

Esqueceu-se, todavia, o ilustre estudioso da Constituição dos Estados Unidos de que circunstâncias eventuais e diversas determinaram os fenôme nos apontados, o que, justamente, patenteia a universalidade do princípio, sua adatabilidade e flexibilidade ante as várias condições reinantes nos diversos países e, sobretudo, não provou êle em que, por exemplo, o parlamentarismo, consagrando o predomínio do poder que encarna, por excelência, a soberania popular, teria destruído o equilíbrio relativo que tem na ordem, na coexistência pacífica das instituições, a sua característica essencial.

Além do mais é mister salientar que o parlamentarismo denuncia uma tendência natural para neutralizar a expansão impressionante e inevitável do executivo na atualidade, patenteando que o discutido princípio da separação dos poderes oferece, em sua aplicação prática, variações que se orientam, precisamente, para o restabelecimento ou a manutenção do equilíbrio cuja perturbação se quer, a êle, equivocamente, atribuir. 
CAPÍTULO II

\section{ANÁLISE DE ALGUMAS APLICAÇÕES MODERNAS DO PRINCÍPIO DA SEPARAÇÃO DOS PODERES}

"A Delegação Legislativa”, "O Direito do Veto" e "O Contrôle da Legalidade dos Atos Administrativos pelo Poder Judiciário"

Antes de analisar algumas aplicações modernas do princípio da separação dos poderes, é mister que em linhas gerais, fixemos a natureza e delimitemos o campo das atribuições dos mesmos, uns perante os outros.

O legislativo é, por excelência, o órgão representativo da soberania popular, essencial aos regimes democráticos e se caracteriza pelo exercício privativo da função de votar e de emitir as leis, no sentido hieràrquicamente mais elevado e substancialmente mais puro do têrmo.

O executivo é aquêle cujo apanágio deve ser a fiel execução da Lei em que pesem as atribuições secundàriamente judiciais a êle outorgadas, por lei, visando, justamente, a mais fiel observância das diretrizes na lei contidas.

O judiciário é o poder encarregado de dirimir as dúvidas suscitadas na aplicação das leis.

A proibição contida no $\S 2 .^{\circ}$ do art. 36 da Constituição Brasileira, quanto a delegação de atribuições, parece-nos não obstante autorizadas objeções de luminares do Direito Constitucional, a consubstanciação da doutrina exata.

Considerados os três poderes como formadores de uma única entidade - o Estado - é evidente que, entre êles, há de existir inequívoca diferenciação funcional e subseqüente independência e soberania no exercício estrito das suas prerrogativas e, ao mesmo tempo, harmoniosa coexistência, permitindo, sob êste aspecto, reconhecer uma interdependência orgânica de poderes que, pela doutrina organicista, não teremos dificuldades em explicar.

Todavia, essa "interdependência" não representa nem delegação de poderes, nem renúncia de atribuições e nem subordinação de uns aos outros órgãos no que tange às suas prerrogativas fundamentais e características e nem real participação de um na função específica de outro.

Tentando simplificar o estudo do problema das interferências de poderes, o professor Themistocles BRAndão Cavalcanti oferece os três seguintes casos:

$\left.1^{\circ}{ }^{\circ}\right)$ A delegação legislativa;

$2 .^{\circ}$ ) O direito de veto;

3. ) O contrôle da legalidade dos atos administrativos pelo Poder Judiciário.

Sôbre o primeiro caso, somos completamente contrários à renúncia de atribuições que êle representa, apesar de preocupar-nos, vivamente, o crescente agravamento do problema do congestionamento do processo legislativo para o qual encontramos, na Constituição da República da Itália de 1948 , uma das mais felizes soluções (Cf. O Processo Legislativo na Europa Ocidental, GEORGES LANGROD, F.G.V., 1954). 
Seja qual fôr a gravidade do problema, cumpre, ao Legislativo, escrupulosamente e por si mesmo, dar solução para o caso, sem sacrifício da própria personalidade.

A propósito, grave costume anotamos, no funcionamento do legislativo, no que se refere aos longos e irresponsáveis recessos e ao escandaloso regime de liberalidade com que é exercida ttão importante função.

Serve de ilustração para o segundo caso, a ocorrência de representantes do povo que, não compareceram mais de três vêzes às sessões do Congresso em um quadriênio e ainda receberam os seus vencimentos integrais, no Brasil.

A propósito das férias parlamentares é oportuno citar o exemplo da Checoeslováquia, onde as duas Câmaras "elegiam, segundo a representação proporcional, permitidas as coalizões, comissões especiais, de 24 membros (16 da Câmara e 8 do Senado) para que, na ausência das Câmaras, pudessem promulgar leis "provisórias" e exercessem as funções de vigilância parlamentar ao poder governamental e ao poder executivo... A legislação podia versar sôbre qualquer matéria, exceto:

a) eleição do presidente da República;

b) modificação de leis constitucionais ou de competência administrativa no's casos que especificava;

c) imposição de encargos novos e duráveis;

d) autorização para declarar guerra (PONTES DE MIRANDA, Comentários à Constituição Brasileira, vol. I, pág. 523).

Na Letônia, o art. 81 autorizava o Conselho de Ministros a promulgar decretos-leis, na ausência da Diéta, a que deveria ser apresentados três dias após a retomada dos trabalhos, sob pena de perderem o vigor. 9 (PONTES DE Miranda, obra citada, vol. I, pág. 523).

A nosso ver, deve ser encontrada uma fórmula mediante a qual jamais falte à Nação o Poder Legislativo, em qualquer época e com a plenitude das suas atribuições.

O racional aproveitamento do trabalho dos congressistas e o estabelecimento de um assessoramentơ técnico amplo e eficiente. são outras medidas a considerar quando se visa a solução do problema do congestionamento do processo legislativo.

Sôbre o Direito de Veto, por muitos denominado Poder de Veto, opinamos que, se bem definida a verdadeira natureza, o verdadeiro sentido, o verdadeiro espírito da instituição dessa faculdade e cuidadosamente analisada i sua execução prática, concluiremos que primeiro, ela não é mais que uma ponderação de quem obedece a quem ordena e, segundo, que só um grave êrro de desrespeito à verdadeira natureza do veto, tem permitido, generalizadamente. o seu exercício na forma com que atualmente é feito. frontalmente contra a Carta Magna de 1946.

Na verdade, o direito de vetar não é mais que a faculdade atribuída ao Chefe do Executiva (que tem por obrigação a fiel observância da Lei) de oferecer objeções à promulgacão desta. desde que a considere inconstitucional ou contrária ao interêsse público. Seria realmente inadmissível dar um poder, uma ordem a outro poder, sem que a êste se outorgasse essa faculdade 
elementar de lembrar que a ordem seria inconstitucional ou seja "null and void" - nula e sem qualquer efeito - na expressão de TUCKER e CoOLEY; sem que fôsse permitido ao poder que obedece o direito de dizer ao poder que manda, que a ordem se cumprida, iria ferir, frontalmente "o interêsse público", patrimônio sagrado que, em resumo, cumpre aos três poderes, salvaguardar.

E', pois evidente, que não basta um simples desacôrdo do Executivo, total ou parcial, para legitimar o exercício do "qualified negative", total ou parcial. Realmente, a um legislador assiste o direito de votar contra um projeto, soberanamente, sejam quais forem as razões íntimas do seu desacôrdo; e só as declarará por sua livre e expontânea vontade. Com o Chefe do Executivo dá-se o contrário isto é, só poderá opor-se a um projeto de lei aprovado pelo Legislativo mediante ampla exposição de suas razões. A êle cumprirá, entretanto, silenciar quaisquer outras objeções que não sejam as que, porventura, bastem para caracterizar os dois transcendentais fundamentos citados.

Seja qual fôr a hipótese, é oportuno citar, aqui, Bielza, quando, analisando a atribuição do veto, comenta, com propriedade depois de situar a posição de uns frente aos outros poderes:

"Pero el Poder Ejecutivo, frente a los otros poderes, no tiene sino una potestad circunstancial y subordinada a la iniciatia. Por ejemplo, puede vetar una ley pero el veto es freno relativo porque la insistencia del Congreso por una mayoria determinada destruye el veto" (RAfael Bielza, "Estudios de Derecho Publico, III, página 116, E. Depalma, Buenos Ayres, 1952).

A nosso ver como já nos externamos em tese sôbre o assunto, "o único efeito definitivo do veto, além do suspensivo (quanto à tramitação do projeto) é o restritivo caso mantido". (ÉLIo SOLON DE PONTES "Da Publicação de Lei, Objeto de Veto Parcial, antes da Apreciação dêste pelo Poder Legislativo" "Rio, D.A.S.P., dezembro de 1954).

Ainda sôbre a matéria, chegamos a elaborar uma tese cujas conclusões, aprovadas pela "IV Semana Nacional de Estudos Jurídicos", realizada em outubro último, em Curitiba presente a fina flor da cultura jurídica acadêmica do país, foram as seguintes:

1. $\left.{ }^{\circ}\right)$ E' considerada viciosa, por contrária a letra da Constituição Federal e incompatível com a natureza do veto suspensivo, limitado, qualificado, relativo, ou condicional nela consagrado, a publicação parcial de projeto de lei, pelo Poder Executivo, antes da apreciação do veto pelo Poder Legislativo;

2. $\left.^{\circ}\right)$ E' recomendada a expressa concessão de regime preferencial e de urgência para a apreciação dos vetos do Poder Executivo, a fim de que não permaneça, indefinidamente. em suspenso, a publicação de que provém a obrigatoriedade da norma elaborada. (Élio Solon DE PONTES - "Direito e Estado em face do Veto").

Não pretendendo tecer mais considerações a respeito, porque o campo é demasiado vasto e comportá-las-ia ilimitadas, passaremos ao derradeiro as- 
pecto da "interferência de poderes": "o contrôle da legalidade dos atos administrativos pelo poder judiciário".

Facultado, amplamente, ao Poder Executivo, o próprio julgamento, em instância administrativa, das dúvidas suscitadas da execução que lhe compete, da lei, e, muito especialmente, considerada a hipótese de serem partes o Estado e um cidadão, com direitos antagônicos, para quem apelaria êste último caso seus direitos, por exemplo, julgasse não acautelados?

A resposta só pode ser uma: o Poder Judiciário, a quem está afeta a elevada função de dirimir as dúvidas suscitadas da execução das leis, muito especialmente nos casos em que o direito e as liberdades individuais se acharem turbadas pelo abuso dos agentes do Poder Executivo.

Nada há, pois, que cause espécie: "o poder detém o poder".

\section{EXPLICAÇÃO ORGANICISTA DA SEPARAÇÃO DOS PODERES} Conclusão

A nosso ver, todos êstes problemas e fenômenos podem ser perfeitamente explicados e justificados pela simples descrição anatômica-funcional do corpo humano.

Fá-lo-emos, aqui, com a ajuda de três geniais autores contemporâneos: H. G. Wells, HUXley e G. P. Wells ("A Ciência da Vida", tradução de V. Coaracy, I, "José Olímpio", Editôra, Rio, 1940).

Desnecessário seria lembrar, inicialmente que os cidadãos figuram, no organismo de um povo, os bilhões de bilhões de células que integram os órgãos do corpo humano.

Pois bem:

"As atividades ordinárias dos órgãos são integrações das atividades das células que os constituem. A contração de um músculo, por exemplo, é, de fato, o esfôrço sincronizado de milhares de células musculares e a bilis é o produto coligido de inumeráveis células hepáticas. E' evidente que esta cooperação só é possível mediante a existência de direção ou "contrôle". Nenhum músculo prestaria serviço se as células que o compõem tivessem liberdade de contrair-se independentemente".

"Estas centenas de músculos que movem a máquina humana são governados por nervos, filamentos de tecido branco, uns espessos e conspícuos, delgados e quase invisíveis outros, que percorrem os músculos e se ramificam por entre êles. Tođos sabem que êstes nervos funcionam como fios telegráficos, trazendo estímulos aos músculos sempre que êstes devam mover-se. Irradiando do cérebro e do seu prolongamento, a medula, fọrmam um sistema não menos complexo do que o muscular, porque cada músculo tem o seu aparêlho nervino. O cérebro e a medula constituem, por assim dizer. o govêrno que dirige os músculos aos quais estão, constantemente, por intermédio dos nervos, transmitindo ordens para que seja feito um movimento aqui, uma contração ou uma distenção ali. Suprimido êste contrôle central, como por exemplo quando um nervo é cortado ou invalidado, o músculo respectivo fica inerte e paralizado". 
E' o que sucederia em caso de uma lei, ao ser revogada, e de falta de lei:

"O cérebro e a medula não exercem ditadura caprichosa e arbitrária. Além de expedir ordens, recebem copiosa corrente de informações provindas de tôdas as regiões do corpo e respondem logo, determinando os movimentos que o mecanismo deve executar em cada caso".

Assim também o Legislativo atua em função das manifestações populares e ouve, até mesmo, o Poder Executivo, através das razões de veto.

"O govêrno central é o cérebro. Seus informantes são os aparêlhos dos sentidos: olhos, ouvidos, nariz, língua, os órgãos do tato e das sensações de calor. de dôr, os instrumentos que sentem o que ocorre a cada instante em nossos músculos, articulações e vísceras. Éstes e muitos outros, ainda, enviam, contìnuamente, mensagens ao cérebro e à medula e os nervos transmitem as informações e trazem as ordens conseqüentes".

"Já comparamos o sistema nervoso a uma rêde telefônica, da qual difere, aliás, pelo fato de que suas fibras funcionam em um só sentido: umas transportam impulsos do centro para a periferia e são as fibras motoras; outras trazem mensagens da periferia para o centro e são as fibras sensitivas. Além do sistema principal ou "sistema nervoso central", existem centros e sistemas subordinados em comunicação mais ou menos íntima com êle. Executam tarefas de coordenação de menor amplitude e com cujos pormenores é desnecessário sobrecarregar o centro principal. Dêsses centros inferiores. o mais notável é o plexo solar".

Tal fenômeno explica a existência dos tribunais administrativos, das cơmissões permanentes de inquérito, das elaborações de decretos. instruções e portarias "para fiel observância da lei".

Diante disso, cabe perguntar-se: como superestimar as instâncias administrativas, essas funções "quase judiciais" (na terminologia americana), confundindo-as com as funções típicas do Poder Judiciário?

\section{CONCLUSÃO}

A personalidade e a independência dos poderes, no exercício de suas específicas atribuições, não exclui uma coordenação uma espécie de interdependência orgânica dos três integrantes do Estado.

Essa mútua dependência, entretanto, não pode, absolutamente, significar a menor tolerânc1a no que tange à delegação das precípuas atribuições e poderes de um a outro poder.

"Na vida animal, um órgão não transmite a outro as suas funções", observa CARLOS MAXIMILIANo, aduzindo:

"Demais, transmitindo a outrem a tarefa que lhe é própria, desmoraliza-se o Legislativo, confessa sua impotência". ("Comentários à Constituição Brasileira", vol. I pág. 407).

Em suma, razão teve KANT para entrever, engenhosamente, nos vários ramos do govêrno, "três pessoas morais", cujos esforços autônomos se coordenam e se completam reciprocamente. No conceito do filósofo de Koenigsberg os poderes constituídos formam como que as três proposições de um 
silogismo prático: a maior contém a lei de uma vontade; a menor, a ordem de proceder de acôrdo com a lei; e a conclusão, a sentença, a qual decide o que é de Direito, no caso de que se trata.

Característicos dos três poderes:

O Legislativo é irrepreensivel;

o Executivo é irresistível;

- Judiciário, inapelável.

Observam-se, é verdade, numerosas variações da aplicação prática do princípio de MONTESQUIEU como, por exemplo, a ocorrência, em certos e determinados períodos, em várias nações, de mais de três poderes constitucionais como foi o caso, no "Império do Brasil" que possuia quatro poderes e a China da atualidade com cinco.

A rigor, porém, três são, universalmente, os poderes e um só o princípio que os rege, na atualidade, em todo o Mundo: o princípio da separação dos poderes, alheio às objeções que se fazem ao seu nome, sobrepairando às dúvidas arguidas quanto ao seu conceito.

Finis coronat opus

Não é inconstitucional, mesmo nos países contrários à delegação de poderes, a participação do executivo na criação do direito objetivo. Regulamentar não é sòmente reproduzir, analiticamente, a lei, mas ampliá-la, segundo o seu espírito e o seu conteúdo. Subordinado à supremacia da lei, o regulamento constitui, por igual, uma das fontes de Direito Administrativo.

O Estatuto (de 1952) é, como o anterior, o centro de gravitação de regulamentos especiais. O regime jurídico de pessoal permanente não se esgota na letra estatutária e reclama a ação regulamentar. Há um vínculo umbilical entre o Estatuto e os regulamentos de execução que o completam e desenvolvem. Muitos dos dispositivos da lei são normas programáticas que sòmente adquirem executoriedade com a complementação regulamentar.

CAIO TÁcito - O Estatuto de 1952 e suas inovações - "Revista de Direito Administrativo" - Vol. 34 - Outubro-Dezembro de 1953 pág. 3. 